\title{
EVALUASI KOMUNIKASI DATA SP2TP ANTARA PUSKESMAS DAN DINAS KESEHATAN DI KABUPATEN TOLITOLI PROVINSI SULAWESI TENGAH
}

\author{
Vidyanto \\ Fakultas Ilmu Kesehatan Universitas Tadulako \\ Email :vid.yanto@gmail.com
}

\begin{abstract}
Information plays an important role in an organization. Information is data that are put into a more meaningful and useful context to be communicated to the interlocutor that support the decision making. SP2TP is a media and information for Primary Health Care that must be reported to health authorities. Therefore, the data communication process needs to be carried out properly and correctly in order to produce qualified data and information. The results of the evaluation program SP2TP in Tolitoli District Health Office in 2010 showed that 3 of 13 Primary Health Care (23:08\%) sent reports timely and completely, and there are 10 Primary Health Care (76.92\%) reporting with a variety of timeliness and completeness. This is a qualitative explorative research. The data were collected by using interview and observation. Subject of the research is the SP2TP Primary Health Care and District Health Office staffs determined by purposive sampling. In one hand, the ability of Primary Health Care as the SP2TP sender is not yet optimal for some causes; the geographical condition of Primary Health Care is difficult, the quality of the human resources is not yet sufficient, the workload is high, there is no electronic media available yet, the supporting facilities are not yet used optimally, the reporting is carried out simply. Those are the obstacles in implementing SP2TP data communication. In other hand, the ability of the District Health Office as the SP2TP recipient is not yet optimal for some causes; the report reception mechanism is complicated, the technology for processing the data is limited, lacks of feedback and sometimes it is not written. Those factors cause the SP2TP reports lack quality.
\end{abstract}

Keywords: Data communication, SP2TP, Primary Health Care, District Health Office, Tolitoli District.

\begin{abstract}
ABSTRAK
Peran informasi sangat penting terhadap organisasi. Informasi merupakan data yang diletakkan ke dalam konteks yang lebih berarti dan berguna untuk dikomunikasikan kepada penerima dalam menunjang pembuatan keputusan. SP2TP merupakan media informasi puskesmas serta wajib dilaporkan ke dinas kesehatan. Untuk itu, proses komunikasi data perlu dilaksanakan dengan baik dan benar, agar menghasilkan data dan informasi berkualitas. Hasil evaluasi program SP2TP Dinas Kesehatan Tolitoli Tahun 2010 ditemukan. Dari 13 puskesmas 3 puskesmas (23.08\%) mengirim laporan tepat waktu dan lengkap, serta masih terdapat 10 puskesmas (76.92\%) dengan ketepatan waktu dan kelengkapan laporan bervariasi. Mengevaluasi komunikasi data SP2TP ditinjau dari segi kemampuan puskesmas sebagai pengirim dan dinas kesehatan sebagai penerima data SP2TP. Penelitian ini merupakan penelitian kualitatif bersifat eksploratif. Pengumpulan data dilakukan dengan wawancara dan observasi. Subjek penelitian adalah petugas SP2TP puskesmas dan dinas kesehatan ditentukan berdasarkan "purposive sampling" Total jumlah responden sebanyak 14 orang. Kemampuan puskesmas sebagai pengirim data SP2TP belum optimal meliputi: Kondisi puskesmas dengan geografis sulit, SDM belum memadai, jumlah tenaga minim, beban kerja tinggi, belum adanya media komunikasi elektronik, fasilitas pendukung belum dimanfaatkan secara maksimal, pengiriman laporan masih dengan cara sederhana, menjadi faktor penghambat terhadap pelaksanaan komunikasi data SP2TP. Kemampuan dinas kesehatan sebagai penerima data SP2TP belum optimal meliputi: mekanisme penerimaan laporan berbelit-belit, minimnya fasilitas teknologi dalam pengolahan data, umpan balik sangat jarang dan bahkan tidak dilakukan secara tertulis, menyebabkan laporan SP2TP dihasilkan kurang berkualitas.
\end{abstract}

Kata Kunci: Komunikasi Data, SP2TP. Puskesmas. Dinas kesehatan. Kabupaten Tolitoli. 


\section{PENDAHULUAN}

Peran informasi sangat penting terhadap organisasi, Informasi merupakan data yang diletakkan kedalam konteks yang lebih berarti dan berguna untuk dikomunikasikan kepada penerima dalam menunjang pembuatan keputusan. ${ }^{1}$ Salah satu sumber informasi manajemen puskesmas (SIMPUS) adalah sistem pencatatan dan pelaporan terpadu puskesmas (SP2TP). ${ }^{2}$ Pelaksanaan komunikasi data SP2TP dari puskesmas pembantu ke puskesmas maupun puskesmas ke dinas kesehatan menemui hambatan, terutama pada puskesmas dengan kondisi geografis sulit, sarana pelayanan kesehatan tersebar di kepulauan dengan akses telekomunikasi tidak tersedia serta pustu terletak di daerah-daerah terpencil. Kondisi ini menyebabkan petugas kesulitan dalam melakukan pengumpulan dan pengiriman laporan SP2TP.

\section{BAHAN DAN CARA}

Penelitian kualitatif bersifat eksploratif. Subjek penelitian adalah petugas
SP2TP puskesmas dan dinas kesehatan ditentukan berdasarkan "purposive sampling" Total jumlah responden sebanyak 14 orang. Pengumpulan data dianalisis dengan menganalisis isi meliputi: proses identifikasi, pengkodean, serta mengkategorisasikan polapola penting dari hasil wawancara mendalam. ${ }^{3}$

\section{HASIL DAN PEMBAHASAN}

\section{Puskesmas Dengan Geografis Sulit}

Berdasarkan hasil observasi diketahui bahwa dari 13 puskesmas terdapat 2 puskesmas memiliki akses sulit seperti Puskesmas Basidondo dan Ogotua. Selain itu, terdapat 3 puskesmas yang wilayah kerjanya luas serta memiliki daerah-daerah terpencil. Puskesmas tersebut diantaranya. Puskesmas Dondo, Laulalang dan Ogodeide. Secara umum kelima puskesmas tersebut berada pada puskesmas wilayah pinggiran dan pedesaan. Lebih jelasnya letak puskesmas dengan kondisi geografis sulit dapat dilihat pada gambar 1 .

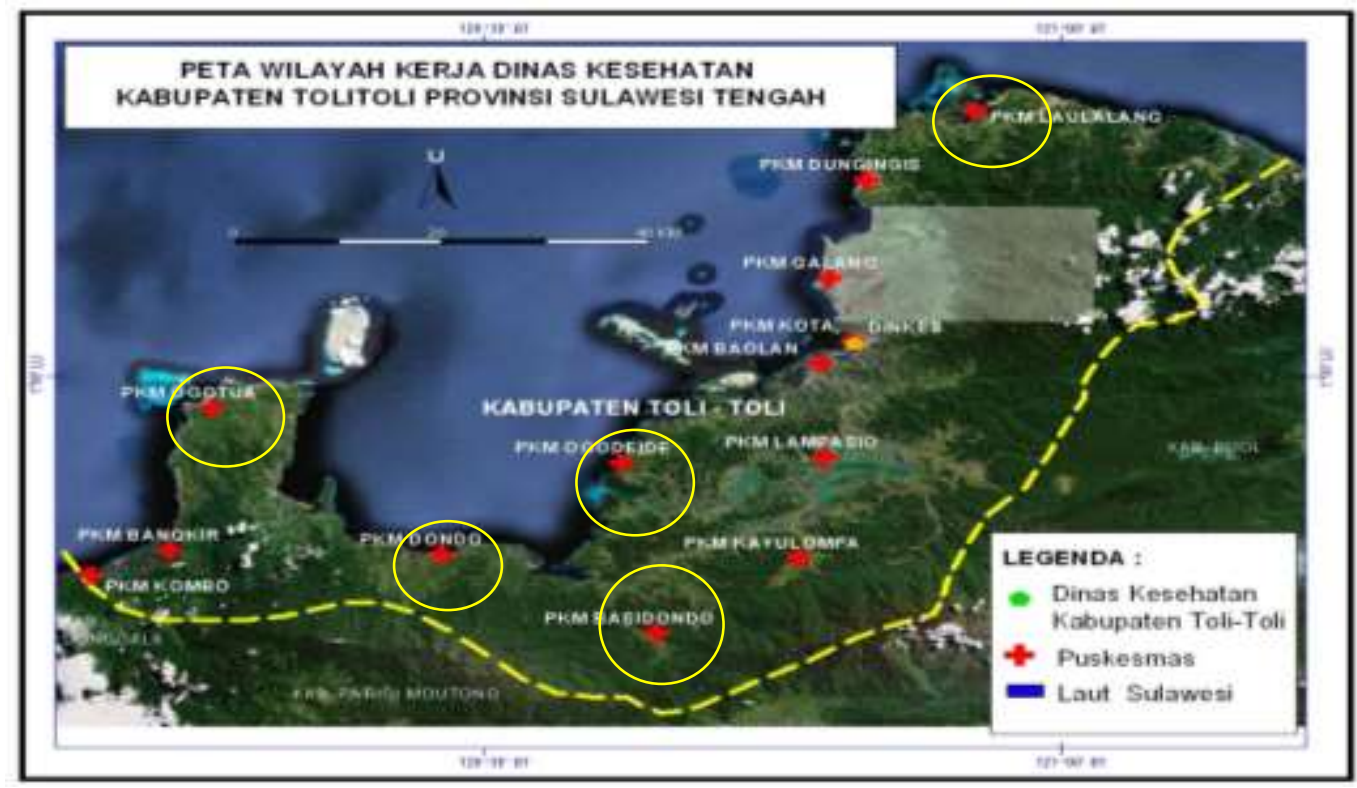

Berdasarkan gambar 1 terlihat bahwa Puskesmas Ogotua, Basidondo, Dondo, Ogodeide, dan Laulalang. Merupakan puskesmas daerah sulit dan memiliki wilayah kerja luas serta terdapat daerah-daerah terpencil. Secara topografis letak puskesmas di Kabupaten Tolitoli berada pada wilayah pesisir, serta Puskesmas Basidondo, Kayulompa dan Lampasio terletak di wilayah dataran tinggi (pegunungan). 
Berdasarkan jarak, rata-rata puskesmas memiliki jarak cukup jauh ke ibukota kabupaten. Untuk itu, Dinas Kesehatan Tolitoli membagi kriteria Puskesmas menjadi 3 (tiga) kriteria diantaranya. Puskesmas Perkotaan dengan jarak 1sampai $12 \mathrm{~km}^{2}$, Puskesmas Pinggiran berjarak 74 sampai $100 \mathrm{~km}^{2}$, dan Puskesmas Pedesaan berjarak 154 sampai $192 \mathrm{~km}^{2}{ }^{4}$

\section{Kemampuan Puskesmas Sebagai} Pengirim Data SP2TP

\section{a. Koordinasi Data Dalam Gedung Dan Luar Gedung}

Koordinasi data SP2TP dilakukan selama ini, untuk mengisi format laporan LB1 dan LB4. Data LB1 dikumpulkan dari hasil kegiatan pelayanan kesehatan dalam gedung maupun luar gedung. Data dalam gedung diambil dari register kunjungan puskesmas meliputi. Register rawat jalan, rawat inap, poli umum, dan UGD (Unit gawat darurat). Data ini merupakan hasil kegiatan yang dicatat setiap hari dan direkapitulasi setiap bulan di puskesmas. Sedangkan data luar gedung, petugas melakukan koordinasi data dengan petugas puskesmas pembantu. Sementara pengisian format laporan LB4, pengumpulan datanya diambil dari hasil kegiatan programprogram di puskesmas. Adapun jenis data dan program yang dibutuhkan meliputi: 1) Program KIA (jumlah ibu hamil, jumlah ibu melahirkan dan jumlah ibu nifas dirawat), 2) Program gizi (jumlah gizi buruk) 3) Program imunisasi (jumlah bayi di imunisasi) dan 4) Program pemberantasan penyakit menular atau P2M (jumlah Diare, Ispa, Malaria, TB paru dan Kusta).

Bagi puskesmas kondisi wilayah kerja sulit koordinasi data belum optimal. Hal ini disebabkan pustunya tersebar di desa-desa terpencil serta tidak dapat mengakses jaringan telekomunikasi. sehingga sering data program dalam gedung maupun luar gedung tidak tersedia jika dibutuhkan. Kondisi ini menyebabkan pengolahan dan pengiriman laporan menjadi terlambat. Pada hal koordinasi data merupakan cara efektif dari berbagai unit/bidang program saling terikat untuk mencapai tujuan organisasi. ${ }^{5}$ Koordinasi data penting dalam pelaksanaan SP2TP disebabkan tanpa adanya koordinasi kegiatan program akan berjalan sendirisendiri yang mempengaruhi kualitas informasi. ${ }^{67}$ koordinasi merupakan sarana konsultasi antar petugas dalam menyediakan data dan informasi agar menunjang perencanaan dan pengambilan keputusan. Koordinasi data akan terlaksana dengan baik jika ditunjang dengan komunikasi yang baik. ${ }^{8}$ Agar meningkatkan arus komunikasi data SP2TP. Sebaiknya mengembangkan sistem komunikasi elektronik. Oleh karena. komunikasi dengan bantuan media elektronik memungkinkan informasi dari pelayanan kesehatan khususnya wilayah sulit dapat dikoordinasikan dengan cepat tentunya ini dapat memudahkan petugas dalam melakukan pengumpulan data dan pengiriman laporan. Penyampaian informasi melalui media elektronik akan mengalihkan informasi secara cepat dan aman. ${ }^{9}$ Peran Dinas Kesehatan Tolitoli diharapkan dapat merencanakan alokasi anggaran diperuntukkan terhadap pengadaan perangkat komunikasi elektronik, sehingga koordinasi data mudah dilaksanakan dalam menunjang komunikasi data SP2TP.
b. Ketersediaan SDM, Jumlah Tenaga, dan Beban Kerja 
Kesiapan sumber daya manusia pengelola program SP2TP puskesmas. Dari segi kuantitas tidak bermasalah. Namun secara kualitas belum sesuai kebutuhan. Saat ini petugas SP2TP merupakan tenaga kesehatan yang fokus pekerjaannya melaksanaan program kesehatan dasar. Sementara mengolah data bukan merupakan tugas utama. Pada hal sebagaimana dijelaskan bahwa salah satu faktor penunjang dalam peningkatkan pelayanan kesehatan ialah terpenuhinya SDM yang cukup baik jumlah, kualitas yang disesuaikan dengan tugas, fungsi dan tanggungjawab. ${ }^{10}$

Sementara dari jumlah tenaga di puskesmas juga bervariasi. Saat ini, jumlah tenaga banyak tertumpuk pada puskesmas wilayah perkotaan, sedangkan wilayah pinggiran dan pedesaan belum sesuai kebutuhan. Persebaran tenaga tidak merata menyebabkan kegiatan programprogram di puskesmas tidak dapat dilaksanakan secara optimal. Bagi puskesmas tenaganya kurang ditemukan satu orang merangkap dua sampai tiga program sekaligus. Kondisi ini mempengaruhi kinerja petugas dalam menyediakan data dan informasi SP2TP. Menurut peneliti kekurangan tenaga di beberapa puskesmas sebenarnya dapat diminimalisir melalui mutasi pada puskesmas yang jumlah tenaganya banyak. Mutasi merupakan proses pengalihan tugas untuk mengantisipasi kekurangan tenaga dalam meningkatkan produksi kerja organisasi. ${ }^{11}$ Agar memenuhi kebutuhan tenaga di puskesmas, sebaiknya Dinas Kesehatan Tolitoli melakukan relokasi tenaga kesehatan pada puskesmas yang memiliki jumlah tenaga berlebihan untuk ditempatkan pada puskesmas yang kekurangan tenaga cara ini dapat dilakukan melalui perekrutan tenaga yang ada sekarang (persediaan) dalam memenuhi kebutuhan tenaga kesehatan pada puskesmas-puskesmas yang diantisipasi. $^{12}$

Minimnya tenaga mempengaruhi kinerja petugas dalam penyusunan laporan SP2TP. Petugas harus melaksanakan kegiatan program-program pada waktu yang bersamaan. Kondisi ini menjadikan petugas tidak fokus pada satu kegiatan program saja disebabkan program lain yang dilaksanakan juga memiliki target dengan batasan waktu yang ditentukan, hal ini menyebabkan pengolahan data SP2TP menjadi tidak optimal. Sehingga sering pengiriman laporan ke dinas kesehatan terlambat dilaksanakan. Penelitian ${ }^{13}$ menemukan beban kerja yang tinggi bagi petugas terhadap pengumpulan dan penyusunan laporan merupakan salah satu penyebab data tidak teragregasi dengan lengkap. Pada hal sebagaimana diketahui sebuah organisasi dalam merencanakan kegiatan harus benar-benar memperhitungkan jumlah tenaga dalam melaksanakan kegiatan program. ${ }^{14}$

Dinas Kesehatan Tolitoli perlu melakukan perbaikan ketenagaan melalui perekrutan tenaga kesehatan, agar pelaksanaan kegiatan program dapat disesuaikan berdasarkan tugas dan tanggungjawab. Pembagian tugas sesuai wewenang dan keterampilan akan menciptakan kinerja baik dalam proses pencatatan dan pelaporan SP2TP. Pembagian pekerjaan total menjadi kegiatan-kegiatan sederhana dapat dilakukan jika tersedianya tenaga memadai. Sehingga kegiatan akan mudah dilaksanakan tentunya ini dapat mengurangi kejenuhan petugas dalam melaksanakan kegiatan dengan target 
pencapaian yang tinggi. Pembagian pekerjaan seharusnya tidak terlalu berat agar kegiatan dapat dilaksanakan seefektif mungkin. ${ }^{6}$ Alternatif selain perekrutan tenaga dapat juga dengan mengembangkan sistem pencatatan elektronik untuk mengantisipasi beban kerja petugas yang memang sangat tinggi.

\section{c. Proses pengolahan Data}

Beradasarkan hasil penelitian menunjukkan bahwa proses pengolahan data SP2TP pada puskesmas di Kabupaten Tolitoli, masih dilaksanakan dengan cara sederhana. Fasilitas komputer yang tersedia belum dimanfaatkan dalam menunjang kelancaran pencatatan dan pelaporan. Hal ini dipengaruhi tingkat pengetahuan dan keterampilan petugas yang rendah. ${ }^{15}$ Penerapan teknologi informasi berbasis komputer erat kaitannya dengan kesesuaian pada ketersediaan perangkat keras (hardware), perangkat lunak (software) dan sumber daya manusia (brainware). Ditemukan sebagian besar puskesmas sudah memiliki fasilitas komputer tentunya ini bukan merupakan masalah. Namun kendalanya lebih pada kesiapan SDM. Untuk itu, petugas harus dibekali dengan kemampuan memadai agar dapat menggunakan sistem dalam meningkatkan kinerja pekerjaan. ${ }^{16}$ pelatihan dan magang dapat meningkatkan kemampuan petugas dalam pengelolaan data SP2TP. Namun kegiatan serupa sangat jarang dan bahkan tidak ada dilaksanakan oleh Dinas Kesehatan Tolitoli. Bagaimana pun orang seharusnya tidak berhenti belajar setelah menamatkan sekolahnya (pendidikan formal) karena belajar adalah suatu proses seumur hidup. ${ }^{17} 18$ sumber daya dalam organisasi perlu terus menerus disusun ulang agar siap pakai melalui kegiatan pendidikan pelatihan dan magang. Dengan demikian diharapkan dapat memperbaiki SDM.

\section{d. Media pengiriman laporan}

Media pengiriman laporan SP2TP dari puskesmas pembantu ke puskesmas dan puskesmas ke dinas kesehatan tidak satu pun petugas dijumpai menggunakan fasilitas teknologi. Melainkan laporan disampaikan masih dengan cara sederhana yakni diantar langsung dengan menggunakan kendaraan roda dua (sepeda motor) sebagai alat transprotasi untuk mengirimkan laporan. Saat ini, tehnologi informasi berupa komputer dan internet sudah tersedia baik di kecamatan maupun dinas kesehatan. Hanya saja sarana dan fasilitas tersebut belum dimanfaatkan sebagai media untuk mengirimkan laporan SP2TP. Bagi puskesmas wilayah perkotaan, pengiriman laporan sangat mudah dilaksanakan karena akses puskesmas dekat dengan dinas kesehatan tentunya ini tidak menjadi masalah. Namun bagi puskesmas yang jaraknya jauh petugas mengirimkan laporan dengan cara dititip kepada petugas lain yang kebetulan memiliki urusan di kabupaten atau dititip pada mobil angkutan umum yang memiliki rute setiap hari ke Ibukota kabupaten. Dengan cara seperti ini sering laporan disampaikan tercecer dan bahkan hilang.

Berdasarkan hasil observasi dan temuan dilapangan saat ini tehnologi informasi berupa komputer dan internet sudah tersedia baik di kecamatan dan dinas kesehatan tentunya ini dapat dimanfaatkan sebagai alat dalam menunjang kelancaran pengiriman laporan terutama bagi puskesmaspuskesmas dengan jarak tempuhnya sangat jauh. 19 Mahalnya informasi disebabkan karena informasi harus cepat 
dan tepat didapatkan. Untuk itu, dibutuhkan bantuan teknologi-teknologi terbaru dalam mengirimkan informasi. Dengan demikian hilang atau tercecernya informasi dapat diminimalisir. Peran teknologi informasi khususnya teknologi komputer dan internet dapat memberikan dampak positif pada perkembangan organisasi dan dipercaya akan memberikan nilai efektifitas dan efisiensi dari sebuah proses komunikasi. ${ }^{20}$ Dinas kesehatan perlu mengembangkan media pengiriman laporan secara elektronik (email) dikarenakan fasilitas internet sudah tersedia, dengan demikian akan mengurangi beban biaya dan waktu dikeluarkan pada proses pengiriman laporan. Hal paling penting ialah agar laporan dapat terjamin keamanannya. Teknologi informasi tidak hanya terbatas pada teknologi komputer digunakan untuk memproses dan menyimpan informasi akan tetapi juga mencakup teknologi komunikasi untuk mengirim, menyebarkan dan mendapatkan informasi dengan cepat. ${ }^{1}$

3. Kemampuan Dinas kesehatan sebagai Penerima Data SP2TP

\section{a. Mekanisme Penerimaan Laporan}

Hasil penelitian bahwa mekanisme penerimaan laporan SP2TP puskesmas di Dinas Kesehatan Tolitoli harus melalui beberapa tahapan prosedur penerimaan surat menyurat dinas kesehatan. Tahapan tersebut dimulai laporan SP2TP puskesmas diserahkan pada bagian umum, kemudian didisposisi ke seksi pelayanan dasar dan rujukan, selanjutnya diserahkan pada pengelola program SP2TP untuk ditindak lanjuti. Kondisi ini menyebabkan laporan SP2TP sering hilang dan tercecer, sehingga menyulitkan pengelola program untuk mendapatkan data dengan cepat.
Proses penerimaan laporan berbelit-belit, menyebabkan laporan dari puskesmas sering tercecer dan salah penanganan pada bidang program lain, hal ini tentunya tidak sesuai dengan petunjuk pengelolaan dan pemanfaatan data SP2TP dimana menjelaskan bahwa laporan SP2TP disampaikan langsung pada pengelola program di kabupaten, agar dapat dengan mudah melakukan Kontrol terhadap laporan diterima. ${ }^{21}$

\section{b. Umpan Balik Laporan}

Pada puskesmas, pelaksanaan umpan balik secara tertulis tidak ada dilaksanakan melainkan umpan balik dilakukan secara lisan pada saat rapat lokakarya mini dilaksanakan. Umpan balik yang disampaikan berupa mengingatkan saja pada petugas puskesmas pembantu agar pada bulanbulan berikutnya dapat lebih tertib dan tepat waktu mengirimkan laporan ke puskesmas. Hal yang sama juga dilakukan oleh petugas dinas kesehatan umpan balik secara tertulis tidak dilaksanakan namun dilakukan secara lisan. Penelitian 22 menemukan bahwa pelaksanaan umpan balik pada sistem surveilens di dinas kesehatan Kabupaten Tabalong Provinsi Kalimantan Selatan tidak dilakukan secara tertulis sehingga hasilnya masih jauh dari standar ditargetkan. Saat ini, jika ada data yang belum masuk dan ditemukan permasalahaan pada laporan SP2TP. Petugas dinas kesehatan akan menyampaikannya secara lisan melalui kepala puskesmas atau petugas lain yang kebetulan datang di kabupaten. Pada hal pemberian umpan balik secara tertulis merupakan sebuah kontrol dalam mengukur keluaran dari sistem informasi, bertujuan jika ada penyimpangan petugas dapat melakukan koreksi untuk 
menyesuaikan terhadap kelemahankelemahan dari laporan disampaikan. ${ }^{19}$

Melihat kondisi dilapangan umpan balik perlu dilaksanakan disamping secara lisan juga secara tertulis. Pemberian umpan balik harusnya dilakukan berkesinambungan minimal setiap 3 bulan sekali baik dari dinas kesehatan ke puskesmas maupun puskesmas ke puskesmas pembantu. Kualitas data dan dampaknya terhadap sistem informasi harus dilihat dari perspektif yang luas tidak saja terfokus pada istilah teknis, seperti alat pengumpulan data dan sistem pelaporan, akan tetapi juga pada mekanisme pendukung lainnya, seperti proses umpan balik berkesinambungan dalam menghadapi permintaan data dengan tetap. ${ }^{23}$ Umpan balik tidak dapat diabaikan dalam pelaksanaan komunikasi data SP2TP dikarenakan komunikasi akan efektif sangat tergantung pada proses umpan balik itu sendiri. ${ }^{24}$ Umpan balik dapat meningkatkan motivasi kerja petugas dalam melaksanakan tanggungjawab secara baik dan benar. ${ }^{25}$ Pemberian umpan balik terhadap laporan SP2TP merupakan bentuk pengawasan dan kontrol dalam pelaksanaan sistem informasi yang merupakan tugas manajemen untuk memperbaiki data. Untuk itu, pelaksanaan pengawasan dapat dilakukan melalui umpan balik secara berkesinambungan. ${ }^{26}$

\section{KESIMPULAN DAN SARAN \\ Kesimpulan :}

1. Kemampuan puskesmas sebagai pengirim data SP2TP belum optimal meliputi: Kondisi puskesmas dengan geografis sulit, SDM belum memadai, jumlah tenaga minim, beban kerja tinggi, belum adanya media komunikasi elektronik, fasilitas pendukung belum dimanfaatkan secara maksimal, pengiriman laporan masih dengan cara sederhana, menjadi faktor penghambat terhadap pelaksanaan komunikasi data SP2TP.

2. Kemampuan dinas kesehatan sebagai penerima data SP2TP belum optimal meliputi: mekanisme penerimaan laporan berbelit-belit, umpan balik secara tertulis tidak dilakukan, menyebabkan laporan dihasilkan kurang berkualitas.

\section{Saran :}

1. Bagi Dinas Kesehatan Tolitoli

a. Perlu mengembangkan sistem pencatatan dan pelaporan berbasis elektronik agar memudahkan komunikasi data antar puskesmas dan dinas kesehatan di Kabupaten Tolitoli.

b. Perlu dilakukan pelatihan secara terencana dan berkesinambungan guna mendapatkan SDM yang terampil dan professional dalam pengolahan data SP2TP.

c. Perlu mempertimbangkan dan merencanakan relokasi tenaga pada puskesmas melihat saat ini tenaga yang tersedia lebih banyak tertumpuk pada puskesmas wilayah perkotaan.

2. Bagi Puskesmas

a. Untuk mengantisipasi beban kerja yang tinggi di puskesmas perlu memanfaatkan teknologi dalam pengolahan data, sehingga pelaporan SP2TP lebih efektif, terkait pemanfaatan teknologi perlu dilakukan pelatihan bagi petugas pengelola data SP2TP.

\section{UCAPAN TERIMAKASIH}

Penulis mengucapkan terimakasih kepada semua pihak yang telah membantu dalam proses penelitian ini. 


\section{DAFTAR PUSTAKA}

1. Kadir. (2002). Pengenalan Sistem Informasi. Yogyakarta: Andi offset

2. Depkes RI. (1997a). Pedoman Sistem Informasi Manajemen Puskesmas. Jakarta.

3. Patton, Q. M. (1991). Metode Evaluasi Kualitatif. Yogyakarta: Pustaka Pelajar.

4. Dinkes. (2010). Profil Kesehatan Kabupaten Tolitoli. Kabupaten Tolitoli.

5. Shortel S.M., Kaluzy, AD (1997) Essential of Health Care Management. USA: Delmar Publishers, International Thompson Publishing Company.

6. Handoko, H. (2008a). Manajemen. Yogyakarta: BPEF-Yogyakarta.

7. Walt, G., Pavignani, E., Gilson, L., \& Buse, K. (1999). Health sector development : from aid coordination to resource management. Health Policy and Planning, 14(3), 207-218.

8. Wijono, D. (1997). Manajemen Kepemimpinan Dan Organisasi Kesehatan. Surabaya: Airlangga University Press.

9. Liliweri, M. S. (2008). Dasar Dasar Komunikasi Kesehatan. Yogyakarta: Pusat Pelajar.

10. Wijono, D. (2008). Manajemen Puskesmas kebijakan Dan Strategi. Surabaya: CV. Duta Prima Airlangga.

11. Hasibuan, D. H. M. S. P. (2000). Manajeman Sumber Daya Manusia. Jakarta: PT Bumi Aksara.

12. Handoko, H. (2008b). Manajemen Personalia Dan Sumberdaya Manusia. Yogyakarta: BPEF-Yogyakarta.

13. Garrib, A., Stoops, N., Mckenzie, A., Dlamini, L., Govender, T., Rohde, J., et al. (2008). An evaluation of the District Health Information System in rural South Africa. S Afr Med, 98(7), 549-552.
14. Azwar, A. (1996). Pengantar Administrasi Kesehatan. Jakarta: Binarupa. Aksara.

15. Bodnar, H George Dan Hopwood, S. (1995). Accounting Information System. (S. Empat, Ed.). Jakarta.

16. Paul, R. J., \& Stergioulas, L. K. (2007). Investigating evaluation frameworks for health information systems, 7, 377-385. doi: 10.1016/j.ijmedinf.2007.08.004.

17. Rachmawati, I. K. (2008). Manajemen Sumber Daya Manusia. Yogyakarta: Andi offset.

18. Nugroho, E. (2008). Sistem Informasi Manajemen. Yogyakarta: Andi offset.

19. Muliyanto, A. (2009). Sistem Informasi Konsep Dan Aplikasi. Yogyakarta: Pustaka Pelajar.

20. Faules, P. R. W. (2005). Komunikasi Organisasi. Strategi Meningkatkan Kinerja Perusahaan. Bandung: PT. Remaja Rosda.

21. Depkes RI. (1997b). Petunjuk Pengelolaan Dan Pemanfaatan Data SP2TP. Jakarta.

22. Mahrita, (2008). Evaluasi Pelaksanaan Sistem Surveilens di Dinas Kesehatan Kabupaten Tabalong Provinsi Kalimantan Selatan. Tesis Minat Kebijakan dan Manajemen Pelayanan Kesehatan, Universitas Gadjah Mada Yogyakarta.

23. Mavimbe, Jorn Braa, A. G. B. (2005). Assessing Immunization Data quality from Routine Reports ini Mozambique. BMC Public Health, 8, 1-8. doi: 10.1186/1471-2458-5-108.

24. Muchlas, M. (2008). Perilaku Organisasi. Yogyakarta: PRESS, GADJAH MADA UNIVERSITY.Ferrario, R. (2003). The impact of technology in organizational communication processes: toward constructivism. 
25. Aqil, A., Lippeveld, T., \& Hozumi, D. (2009). PRISM framework : a paradigm shift for designing, strengthening and evaluating routine health information systems. Health Policy and Planning, 217228. doi: 10.1093/heapol/czp010.

26. WHO. (2008). Framework and Standards for Country Health Information Systems. World Health. 